\title{
Current treatment of hepatitis C-associated rheumatic diseases
}

\author{
Clodoveo Ferri',*, Marco Sebastiani', Alessandro Antonelli², Michele Colaci', A Manfredi' and Dilia Giuggioli'
}

\begin{abstract}
The hepatitis $\mathrm{C}$ virus (HCV) is both hepatotropic and lymphotropic, responsible for a great number of hepatic and extrahepatic immune-system disorders that comprise the so-called HCV syndrome. HCV-associated rheumatic diseases are characterized by frequent clinico-serological overlap; therefore, correct classification of individual patients is necessary before therapeutic decisions are made. This is particularly difficult to do, however, because of the coexistence of viral infection and complex autoimmune alterations. In this context, mixed cryoglobulinemia syndrome (MCs) represents the prototype of virus-related autoimmune-lymphoproliferative diseases. MCs can be treated at different levels by means of etiological treatment with antivirals (peg-interferon-alpha plus ribavirin) aimed at HCV eradication and/or pathogenetic/symptomatic treatments directed to both immune-system alterations and the vasculitic process (rituximab, cyclophosphamide, steroids, plasmapheresis, and so on). In clinical practice, the therapeutic strategy should be modulated according to severity/activity of the MCs and possibly tailored to each individual patient's conditions. Cryoglobulinemic skin ulcers may represent a therapeutic challenge, which should be managed by means of both local and systemic treatments. HCV-associated arthritis should be differentiated from the simple comorbidity of HCV infection and classical rheumatoid arthritis. It may be treated with low doses of steroids and/or hydroxychloroquine; the use of biologics (rituximab) may be considered in more severe cases. Primary Sjögren's syndrome is rarely associated with HCV infection, while sicca syndrome and myalgia are frequently detectable in hepatitis $C$ patients, with or without cryoglobulinemic vasculitis. Other autoimmune rheumatic disorders (poly/dermatomyositis, polyarteritis nodosa, osteosclerosis, fibromyalgia, and so on) have been reported as potentially associated with HCV infection in patient populations from different countries, suggesting the role of genetic and/or environmental co-factors. The therapeutic approach to these disorders should be decided according to each individual patient's evaluation, including hepatic, virological, and immunological findings.
\end{abstract}

\section{Introduction}

Following the discovery of hepatitis $\mathrm{C}$ virus (HCV) in 1989 as the major etiological agent of non-A-non-B chronic hepatitis [1], some epidemiological studies suggested its possible role in the pathogenesis of mixed cryoglobulinemia syndrome (MCs), which now represents the prototype of $\mathrm{HCV}$-associated autoimmunelymphoproliferative disorders [1-4]. Since the disease may mimic numerous immunological and neoplastic disorders, the discovery of its association with $\mathrm{HCV}$ infection prompted further clinical investigations into the possible pathogenetic role of $\mathrm{HCV}$ in other autoimmune diseases [2,3]. In 2007, we proposed the term

*Correspondence: clferri@unimo.it

'Rheumatology Unit, University of Modena and Reggio Emilia School of Medicine, 41100 Modena, Italy

Full list of author information is available at the end of the article
'HCV syndrome', which encompasses the wide spectrum of both hepatic and extrahepatic HCV-associated autoimmune diseases, including some malignancies [4]. Figure 1 shows the variable strength of association between $\mathrm{HCV}$ and different diseases in the context of $\mathrm{HCV}$ syndrome.

The pathogenesis of various $\mathrm{HCV}$-associated disorders is quite complex and still not completely understood. $\mathrm{HCV}$ infection is the underlying condition that generally precedes by a long time interval the clinical appearance of extrahepatic diseases. The development of different clinical phenotypes is probably the consequence of multifactorial and multistep processes together with decisive contributions by both genetic and environmental co-factors [1-4]. This hypothesis is in keeping with the strong geographical heterogeneity in the prevalence of different HCV-associated diseases [1,3]. HCV lymphotropism [5] is responsible for the B-lymphocyte expansion responsible for the production of large amounts of circulating immune complexes, mainly mixed cryoglobulins with rheumatoid factor activity, as well as various 


\section{HCV-related rheumatic diseases in the setting of HCV syndrome}

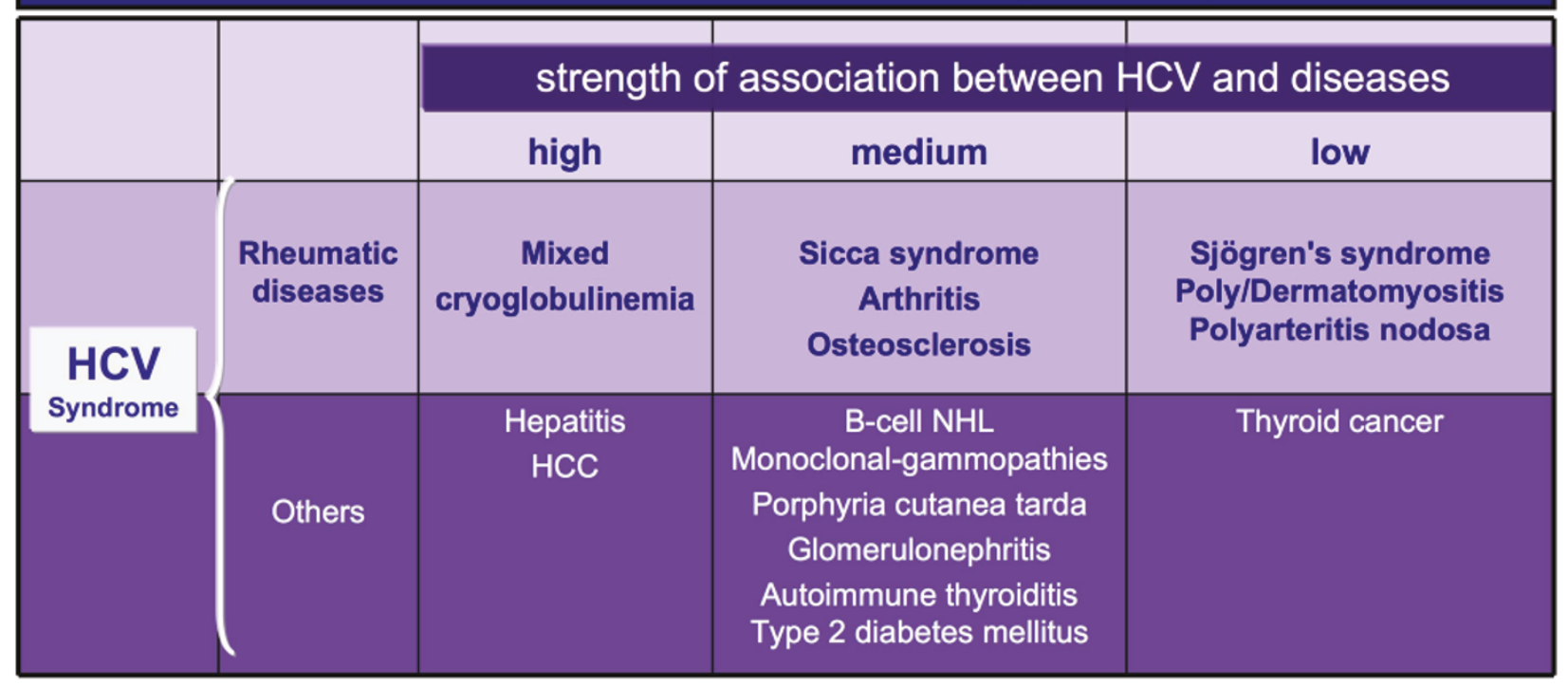

Figure 1. Strength of association between hepatitis $\mathrm{C}$ virus and different diseases in the context of hepatitis $\mathrm{C}$ virus syndrome. The spectrum of different hepatitis C virus (HCV)-associated immunological and neoplastic disorders may be classified on the basis of clinicoepidemiological, histopathological, and molecular biology studies in three different levels. High: the association with HCV infection characterizes the large majority of patients; HCV infection is one of the major triggering agents of the disease. Medium: patients with the disease show a significantly higher prevalence of HCV infection compared to controls; the putative pathogenetic role of HCV is also supported by pathogenetic studies and it may identify at least a specific disease subset. Low: the possible association is suggested by limited clinico-epidemiological observations; a pathogenetic link in at least a specific disease subset from some geographical areas is probable, but needs to be definitely demonstrated. Other possible associations have been suggested (see text) on the basis of anecdotal observations. B-cell NHL, B-cell non-Hodgkin's lymphoma; HCC, hepatocellular carcinoma.

organ- and non-organ-specific autoantibodies [1]. Interestingly, the same immunological alterations may also be observed in a significant percentage of individuals with isolated HCV infection $[1,6]$.

$\mathrm{HCV}$ is a positive, single-stranded RNA virus without a DNA intermediate in its replicative cycle, so that viral genomic sequences cannot be integrated into the host genome. Much evidence indicates that $\mathrm{HCV}$ infection results in chronic stimulation of the immune system, which facilitates the clonal B-lymphocyte expansion $[1,2,7]$. Figure 2 (left side) summarizes both virus- and host-related co-factors, together with the main biological alterations, of the pathogenetic cascade. The result may be classical MCs or other autoimmune disorders, as well as some malignancies, mainly B-cell non-Hodgkin's lymphoma (B-NHL) [1]. Besides MCs, other rheumatic diseases can be related to this virus with variable strength of association $[1,3,8,9]$. The present review focuses on the clinical-serological assessment and therapeutic approach to the main $\mathrm{HCV}$-associated rheumatic disorders.

\section{Mixed cryoglobulinemia (cryoglobulinemic vasculitis)}

The pathological hallmark of MCs is the leukocytoclastic vasculitis of small arteries, capillaries, and venules; therefore, the disease is currently classified among systemic vasculitides, in the setting of small-vessel vasculitides, and the terms MCs and cryoglobulinemic vasculitis should thus be related to the same clinicopathological condition [1]. MCs represents the crossroad between classical rheumatic diseases, such as rheumatoid arthritis (RA) and primary Sjögren's syndrome (pSS), and other autoimmune lymphoproliferative disorders [1] (Figure 1). It is characterized by the typical clinical triad of purpura, weakness, and arthralgias and by multisystem organ involvement $[1,2]$. The typical cutaneous and visceral organ involvements, such as purpura, skin ulcers, and glomerulonephritis, are the consequence of the vessel deposition of circulating immune complexes, mainly mixed cryoglobulins and complement [1]. Liver involvement, generally a mild to moderate chronic hepatitis, may evolve to frank cirrhosis in a minority of patients, and is rarely complicated by hepatocellular carcinoma [4]. Renal involvement is often responsible for membranoproliferative glomerulonephritis type I; it may severely affect the overall prognosis of patients with MCs, often in combination with liver damage [4]. Peripheral neuropathy and skin ulcers are quite frequent manifestations of MCs; they are barely responsive to treatments and consequently may 


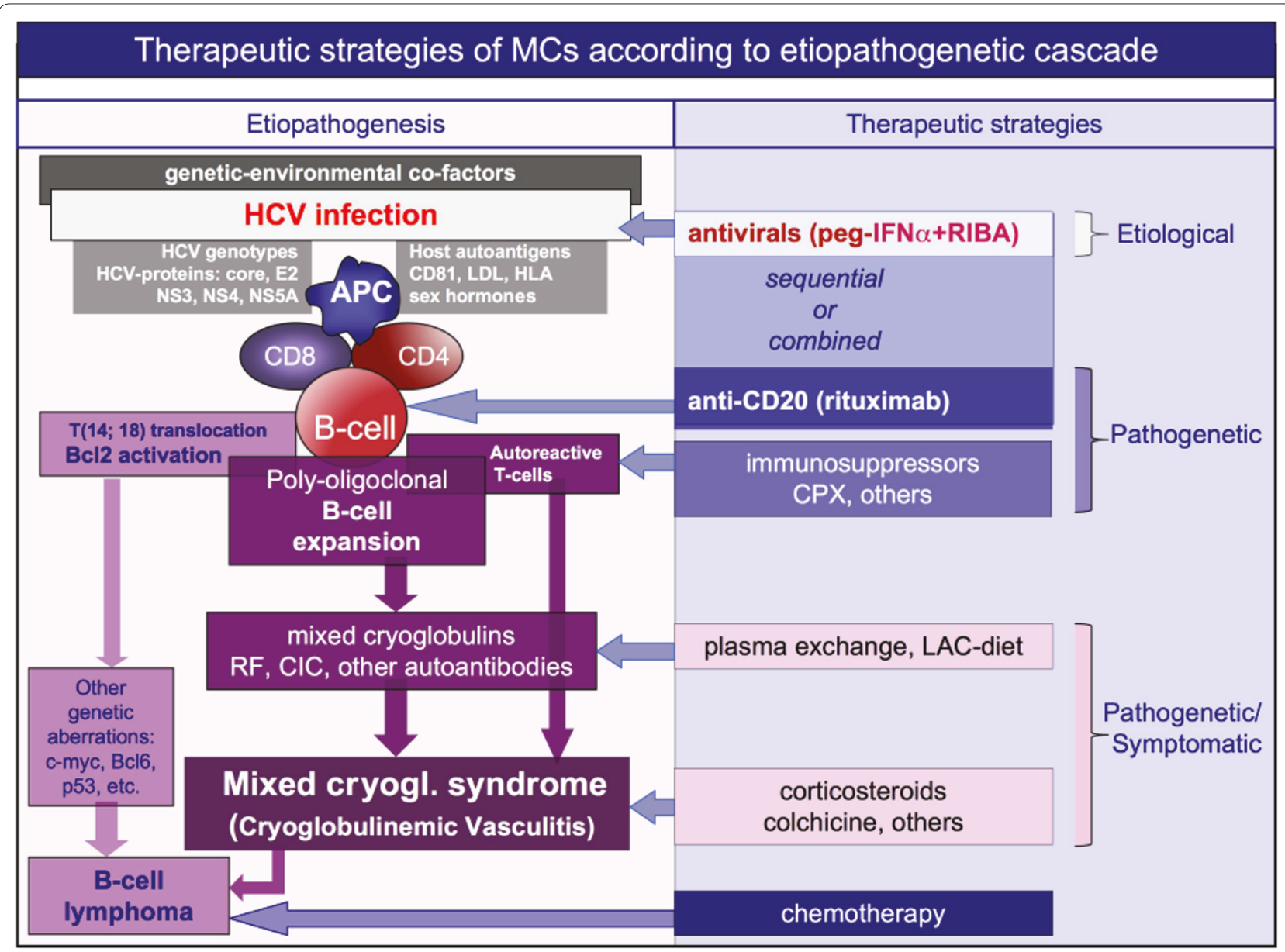

Figure 2. The treatment of mixed cryoglobulinemic syndrome must be decided on the basis of the etiopathogenetic cascade that leads from hepatitis C virus infection to multiple immune-system alterations, mainly B-cell proliferation, and lastly to immune complexmediated small vessel vasculitis. The vasculitic syndrome may be complicated by malignancies, mainly B-cell lymphoma. Accordingly, we can treat mixed cryoglobulinemic syndrome (MCs) at three different levels by means of etiological, pathogenetic, and symptomatic therapies. The use of antivirals, namely peg-interferon-alpha (peg-IFNa) plus ribavirin (RIBA), aims to eradicate the hepatitis C virus (HCV); it represents the etiological treatment of HCV-associated MCs. The anti-CD20 monoclonal antibody rituximab is considered the most useful and safe pathogenetic treatment of MCs. In selected patients with severe, active clinical manifestations, sequential or combined therapy with antivirals and rituximab has been usefully employed (see also Figure 3). CIC, circulating immune complexes; CPX, cyclophosphamide; HLA, human leukocyte antigen; LAC, low antigencontent; LDL, low-density lipoprotein; RF, rheumatoid factor.

compromise the patient's quality of life [4]. Finally, BNHL and widespread vasculitis may complicate a minority of cases; they represent the most harmful manifestations of the disease $[1,2,4]$. Besides mixed cryoglobulins in serum, marked reduction of hemolytic complement activity, with the typical pattern of low, often undetectable complement C4, is another hallmark of the disease and is particularly useful for disease classification $[1,10,11]$. However, both complement levels and cryocrit rarely correlate with the activity/severity of MCs; consequently, they are not very useful for clinical monitoring of patients and therapeutic decision-making. In contrast, the correct evaluation of B-cell expansion, which represents the biological substrate of MCs, is mandatory because of the possible complication of overt lymphoma $[1,2,7]$. This latter event should be suspected in the presence of rapid increases of cryocrit and serum levels of monoclonal rheumatoid factor and/or complement C4 [1].

The treatment of $\mathrm{HCV}$-associated MCs is particularly challenging due to the complex etiopathogenesis and clinical polymorphism of the disease. In fact, we can treat $\mathrm{MCs}$ at three different levels (Figure 2): the chronic $\mathrm{HCV}$ infection; the immune-pathological alterations, mainly Blymphocyte proliferation; and the immune complexmediated cryoglobulinemic vasculitis $[1,3]$. Moreover, the correct evaluation of different clinical phenotypes, varying from mild purpuric lesions, arthralgias, and/or 
weakness to severe organ involvement (renal, liver, diffuse vasculitis) or malignancies (B-NHL), should direct our therapeutic interventions (Figure 3).

$\mathrm{HCV}$ infection results in chronic stimulation of the immune-system [7], and it may also be responsible for either liver damage or neoplastic complications; in theory, $\mathrm{HCV}$ eradication using alpha-interferon and ribavirin should be attempted in all cases $[1,3,12,13]$. However, a beneficial effect of antivirals may be recorded in less than half of treated patients and they are often associated with important immune-mediated side effects, such as peripheral sensory-motor neuropathy, thyroiditis, and rheumatoid-like polyarthritis $[1,3,14]$. It is plausible that alpha-interferon, which is both an antiviral and immunomodulating agent, can foster or exacerbate these symptoms, possibly in predisposed subjects.

In the near future, a vaccine-based therapy [15] might be able to prevent the progression of $\mathrm{HCV}$ infection and possibly to interrupt the self-perpetuating autoimmune mechanism underlying MCs.

Preliminary studies suggested that some immunomodulating therapies in association with antiviral treatment, namely cyclosporine A or TNF inhibitors, have synergistic effects in the setting of chronic hepatitis type C $[16,17]$.

Besides etiological treatments, immunomodulating/ immunosuppressive drugs represent the most useful therapies able to affect the main pathogenetic mechanisms of MCs, including T- and B-cell proliferation and autoantibody production. These treatments include cyclophosphamide and an anti-CD20 monoclonal antibody (rituximab) [1,3]. During the past decade, rituximab has been increasingly employed for both cutaneous and visceral organ involvement of MCs; it can be regarded as a useful and safe pathogenetic treatment of cryoglobulinemic vasculitis [18]. Its safety was also confirmed in patients with liver damage; interestingly, in patients with $\mathrm{HCV}$-associated MCs and advanced cirrhosis, treatment with rituximab was able to improve both the cryoglobulinemic vasculitis and liver function [19]. A comprehensive analysis of the literature regarding the use of rituximab and its role in the therapeutic strategy of MCs patients has been recently published [18]. Very recently, the results of a randomized controlled trial demonstrated that anti-CD20 monotherapy also represents a useful and safe option for patients with severe MCs [20].

Among symptomatic/pathogenetic treatments, a low antigen-content diet can improve the clearance of circulating immune complexes by restoring the activity of the reticulo-endothelial system, which becomes overloaded by large amounts of circulating cryoglobulins [1]. This reduction in the alimentary input of macromolecules with potential antigenic activity may improve the function of the mononuclear phagocytic system, which is normally impaired in MCs [21]. A low antigen-content diet can be usefully employed in patients with clinically mild MCs symptoms (arthralgias, weakness, sporadic purpura, and/or mild sensory peripheral neuropathy), often in association with low doses of steroids (6-methylprednisolone 2 to $4 \mathrm{mg} /$ day) and/or colchicine. Most patients show only mild symptoms for a long time period, and are particularly sensitive to symptomatic treatments and to small doses of daily steroid ( 1 to $2 \mathrm{mg}$ ). Clinically asymptomatic patients do not usually need any treatment, even in the presence of high levels of cryocrit, but patients with severe vasculitic manifestations must be promptly treated with high doses of steroids and/or plasma exchange and/or immunosuppressors; this combination therapy is often able to improve the most harmful disease complications (Figure 3) [1,4,22].

The treatment of cryoglobulinemic skin ulcers is particularly challenging. These lesions are prevalent in the lower limbs, where other pathogenetic co-factors may be associated - namely, venous insufficiency and/or arteriosclerotic alterations, which are not rare in older patients with comorbidities and/or who have received long-term steroid treatment. The skin ulcers are painful, non-healing, and often complicated by local infection and they may severely affect patients' quality of life [4]. Figure 4 summarizes the therapeutic strategy for treating cryoglobulinemic skin ulcers, including both systemic and local treatments at a wound care clinic [23]. The long-term administration of analgesics is often necessary to improve the patient's chronic pain and their compliance with local wound care. A team of operators with specific experience should carry out this integrated therapeutic approach $[18,23,24]$.

More recently, some studies have suggested that sequential or combined antiviral and immunosuppressive therapy could represent a rather useful therapeutic strategy for treating MCs $[18,25,26]$. This more aggressive treatment could be particularly indicated in patients with major clinical manifestations and/or inadequate remission after standard treatments.

On the whole, careful monitoring of a patient's clinical status is mandatory in clinical practice, with particular attention paid to neoplastic complications; in all instances the treatment should be tailored to the individual patient according to the severity of their MCs symptoms (Figure 3) [1].

Given the rarity of the disease and the difficulties of recruiting clinically homogeneous series of patients, there are few controlled randomized trials evaluating the usefulness of proposed treatments for MCs. The results of a consensus conference based on the available published studies and expert opinions have been summarized in a preliminary core set of therapeutic recommendations [27]. 


\begin{tabular}{|c|c|c|c|}
\hline asymptomatic & $\begin{array}{l}\text { mild-moderate } \\
\text { purpura, weakness, } \\
\text { arthralgias } \\
\text { mild sensory neuropathy }\end{array}$ & $\begin{array}{l}\text { moderate-severe } \\
\text { active chronic hepatitis } \\
\text { glomerulonephritis } \\
\text { skin vasculitis }\end{array}$ & $\begin{array}{l}\text { severe-rapidly } \\
\text { progressive } \\
\text { glomerulonephritis } \\
\text { sensory-motor } \\
\text { neuropathy } \\
\text { widespread vasculitis }\end{array}$ \\
\hline $\begin{array}{l}\text { monitoring } \\
\text { (HCV eradication } \\
\text { peg-IFN+Riba?) }\end{array}$ & $\begin{array}{c}\text { low-medium dose CS } \\
\text { +/- LAC-diet } \\
\text { +/- other symptomatics } \\
\text { (peg-IFN+Riba?) }\end{array}$ & $\begin{array}{l}\text { peg-IFN+Riba } \\
\text { low-medium dose CS } \\
\text { +/- RTX }\end{array}$ & $\begin{array}{l}\text { plasma-exchange } \\
+ \text { CS } \\
\text { + CPX (or RTX) }\end{array}$ \\
\hline \multicolumn{2}{|c|}{$\begin{array}{c}\text { severe-active manifestations } \\
\text { Glomerulonephritis, skin ulcers } \\
\text { sensory-motor neuropathy, widespread vasculitis }\end{array}$} & \multicolumn{2}{|c|}{$\begin{array}{l}\text { active chronic hepatitis } \\
+ \text { minor MCs symptoms }\end{array}$} \\
\hline \multicolumn{2}{|c|}{$\begin{array}{l}\text { sequential (or combined) treatment } \\
\text { Rituximab ---> peg-IFN+Riba }\end{array}$} & \multicolumn{2}{|c|}{$\begin{array}{c}\text { sequential (or combined) treatment } \\
\text { peg-IFN+Riba ---> Rituximab }\end{array}$} \\
\hline \multicolumn{4}{|c|}{$\begin{array}{l}\text { Figure 3. The therapeutic strategy for mixed cryoglobulinemic syndrome may be modulated according to the clinical status of individua } \\
\text { patients. We can consider at least four clinical conditions. Mixed cryoglobulinemic syndrome (MCs) may be completely asymptomatic or it may } \\
\text { sporadically show very mild manifestations, such as fleeting purpuric lesions on the legs; in these cases monitoring may be sufficient, while an } \\
\text { attempt at HCV eradication may be considered. On the opposite side are patients with severe, rapidly progressive cryoglobulinemic vasculitis } \\
\text { that must be treated with aggressive combined treatment similar to that used for other systemic vasculitides. Sequential or combined treatment } \\
\text { with antivirals and rituximab may be usefully employed in selected patients with severe manifestations. The order of sequential treatment may } \\
\text { be decided on the basis of prevalent organ manifestation(s), even if the combined therapy seems to be comparable for efficacy and safety. CPX, } \\
\text { cyclophosphamide; CS, corticosteroid; LAC, low antigen-content; peg-IFN, peg-interferon; RIBA, ribavirin; RTX, rituximab. }\end{array}$} \\
\hline
\end{tabular}

\section{Sicca syndrome/Sjögren's syndrome}

A possible pathogenetic role of $\mathrm{HCV}$ in pSS has been reported in anecdotal clinical observations [28]. In contrast, the frequent association between sicca syndrome and HCV infection has been demonstrated by both experimental and epidemiological studies focusing on the presence of chronic lymphocytic sialadenitis in patients with HCV infection [29]. HCV can replicate within epithelial cells of the salivary gland of patients with sicca syndrome and HCV infection [30].

In clinical practice, the correct differential diagnosis between some $\mathrm{HCV}$-associated rheumatic disorders and classical rheumatic diseases is still under debate, in particular between MCs and pSS; this probably reflects the lack of standard classification of these diseases in different referral centers.

Figure 5 shows the main clinico-pathological and immunological differences between $\mathrm{MCs}$ and other possible $\mathrm{HCV}$-associated diseases. Patients with MCs may develop a mild sicca syndrome in the absence of typical histopathological and/or serological alterations [1]. On the other hand, the detection of mixed cryoglobulins in the serum of a minority of pSS cases seems to identify a particular clinical subset characterized by worse prognosis and frequent evolution to malignant B-NHL [31]. In individual cases the differential diagnosis between PSS and MCs may be very difficult, mainly in patients with overt sicca syndrome, cryoglobulinemia, and HCV infection [1]. Therefore, it is correct to classify these patients as overlapping MCs/pSS [1], and the therapeutic approach should consequently be decided after careful evaluation of the main clinical manifestation(s), including the presence/severity of type $\mathrm{C}$ hepatitis.

Antiviral treatment with IFN $\alpha$ and ribavirin seems to improve sicca syndrome in $\mathrm{HCV}$-positive patients, even if serious immune-mediated adverse events have been observed [32]. Besides topical treatments that may 


\begin{tabular}{|c|c|}
\hline Systemic treatment & Local treatment \\
\hline $\begin{array}{l}\text { Etiological: } \\
\text { - antivirals (peg-IFN+Riba) } \\
\text { Pathogenetic: } \\
\text { - immunosuppressors (RTX or CPX) } \\
\text { - steroids } \\
\text { - plasmapheresis } \\
\text { Symptomatic: } \\
\text { - low dosage steroids } \\
\text { - analgesics }\end{array}$ & $\begin{array}{l}\text { Wound bed preparation: } \\
\text { - remove necrotic tissue } \\
\text { - prevent/treat infections } \\
\text { - Moisture balance } \\
\text { - stimulate epithelial advancement } \\
\text { Growth factors: } \\
\text { - platelet gel } \\
\text { Autologous skin grafting }\end{array}$ \\
\hline
\end{tabular}

Figure 4. Therapeutic strategy for treating cryoglobulinemic cutaneous ulcers should be based on both systemic and local treatments. After clinical work-up considering the entire MCs, including possible comorbidities (venous insufficiency and/or arteriosclerotic alterations, diabetes, and so on), and careful examination of the ulcer characteristics, the systemic treatment may be based on etiological, pathogenetic, and/ or symptomatic therapies. More aggressive combined treatments (immunosuppressors, steroids, and plasmapheresis) may be necessary in the presence of very severe, non-healing skin ulcers. Long-term administration of analgesics is often necessary to improve the patient's chronic pain and compliance with local treatment, which should be carried out at a wound care clinic. Wound bed preparation, with particular regard to the prevention and treatment of infections, is crucial for the healing of cryoglobulinemic skin ulcers. CPX, cyclophosphamide; peg-IFN, peg-interferon; RIBA, ribavirin; RTX, rituximab.

partially improve patients' quality of life, there is no specific systemic treatment for $\mathrm{HCV}$-associated sicca syndrome. As for classical MCs or pSS, the possible complication with malignant lymphomas must also be taken into account in these patients [28,31].

\section{Arthritis}

While arthralgias are one of the most common extrahepatic manifestations of HCV infection, chronic arthritis is significantly less common $[4,8,9]$. When present, it is often a less aggressive oligo-polyarthritis compared to classical RA. Patients with $\mathrm{HCV}$-associated MCs present with arthralgias, while inflammatory joint involvement is quite rare and generally characterized by mild oligoarthritis [4]. A symmetrical rheumatoid-like polyarthritis may complicate IFN treatment in $\mathrm{HCV}$-positive patients [9]. Because of the relatively high prevalence of the two diseases, it is not rare to observe a simple association between classical RA and $\mathrm{HCV}$ infection. Figure 5 summarizes the main clinico-serological parameters for differential diagnosis between classical RA and other HCV-associated disorders $[1,3,4,8,28,31,33,34]$. In patients presenting with chronic arthritis, the presence of hepatotropic virus infection (that is, HCV and hepatitis B virus) must be ruled out because of the possible severe, often life-threatening side effects of disease-modifying antirheumatic drugs (DMARDs) and biologics [35]. Several different viral infections may trigger symmetrical arthritis mimicking classical RA and clinical work-up including virological investigations should therefore be done at the patient's first assessment (Figure 6).

Patients who present with both $\mathrm{HCV}$ infection and arthritis can either have a simple comorbidity of RA and $\mathrm{HCV}$ infection or $\mathrm{HCV}$-associated arthritis, with or without MCs. The first may be treated with standard strategies used for RA with some precautions in consideration of the concomitant viral infection and possible liver involvement. Some DMARDs, in particular methotrexate and leflunomide, may be employed after carefully evaluating and monitoring liver involvement, while biologics such as anti-TNF $\alpha$ and rituximab have been usefully employed without significant side effects in $\mathrm{HCV}$-positive RA patients [36]. Interestingly, these biologic therapies, as well as cyclosporine A, seem to have a potential synergistic effect with antiviral treatments for hepatitis C $[16,17]$. Therefore, careful hepatologic evaluation of these patients is always mandatory, taking into account the opportunity for antiviral treatment [35].

On the whole, patients with concomitant RA and HCV infection require the same clinical assessment and monitoring as patients with $\mathrm{HCV}$-associated arthritis with or without MCs; they may have an increased risk to develop some $\mathrm{HCV}$-associated complications, such as B-cell NHL, even as a consequence of immunomodulating therapies. 


\section{Main HCV-related rheumatic diseases: differential diagnosis}

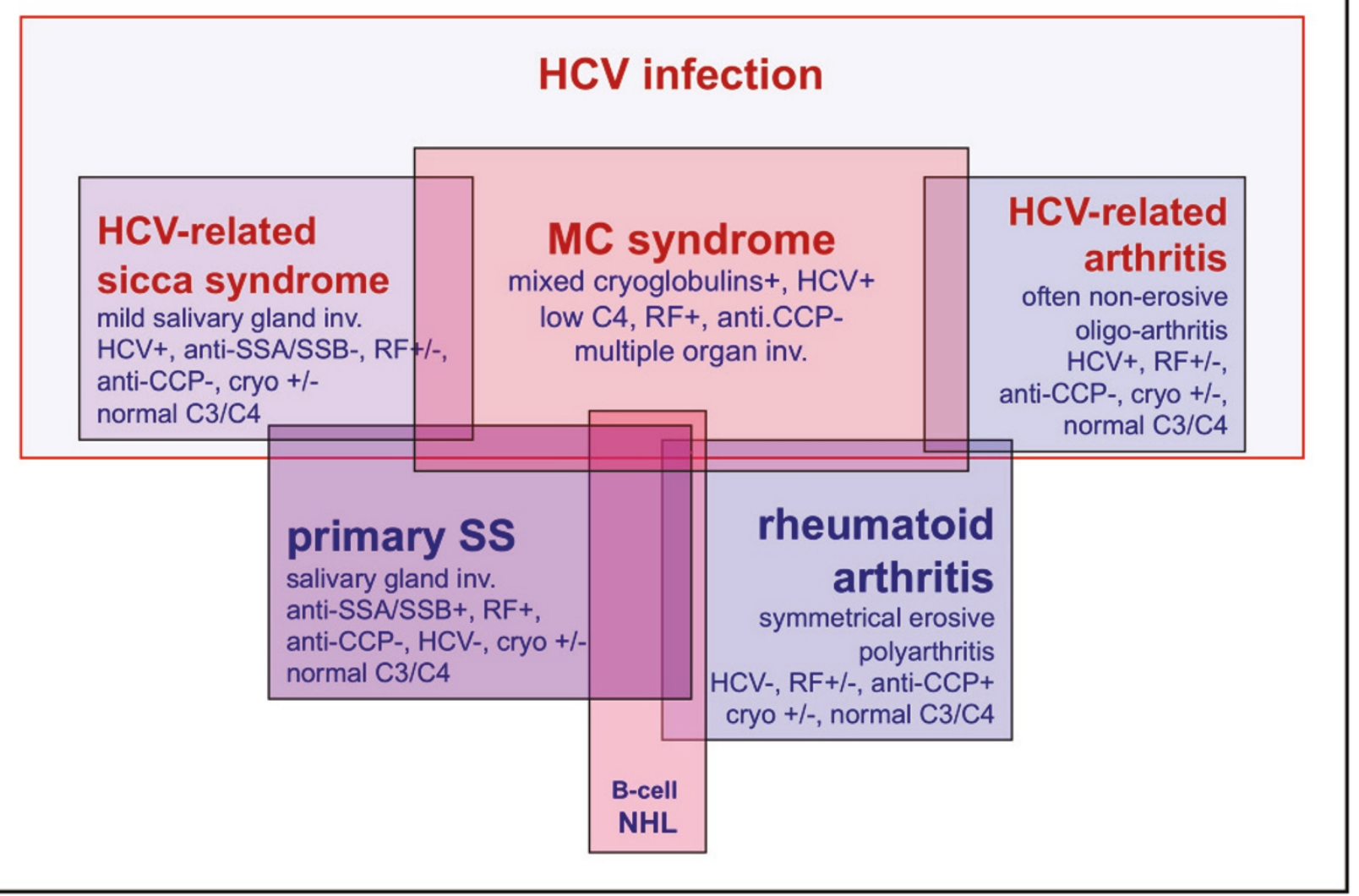

Figure 5. Differential diagnosis between some important hepatitis $C$ virus-associated rheumatic manifestations and classical diseases such as primary Sjögren's syndrome and rheumatoid arthritis is possible on the basis of clinico-serological and pathological features. Some important findings may be usefully employed for a correct diagnosis: the histopathological characteristics and severity of salivary gland involvement and specific autoantibodies (anti-SSA/SSB) are rarely found in hepatitis C virus (HCV)-associated sicca syndrome or mixed cryoglobulinemia syndrome (MCs) patients. Conversely, cutaneous leukocytoclastic vasculitis, visceral organ involvement (hepatitis, membranoproliferative-glomerulonephritis), abnormally low complement $\mathrm{C} 4$, and HCV infection, typically found in $\mathrm{MCs}$, are very uncommon in primary Sjögren's syndrome (pSS). Both MCs and pSS may be complicated by B-cell non-Hodgkin's lymphoma (B-cell NHL), and less frequently also rheumatoid arthritis patients. Finally, erosive symmetrical polyarthritis and serum anti-cyclic citrullinated peptide (anti-CCP) antibodies are specific diagnostic findings of classical rheumatoid arthritis, but generally absent in HCV-associated arthritis. However, there is a gray area of clinical overlap between different disorders. RF, rheumatoid factor.

Usually, HCV-associated arthritis is poorly aggressive and the patients may respond to low doses of steroids and hydroxychloroquine. The use of other DMARDs presents the above-mentioned limitations. On the contrary, rituximab may be usefully employed, mainly in patients with more aggressive disease, and may represent the first-choice treatment in patients with arthritis in the setting of MCs [18].

\section{Other possible HCV-related rheumatic diseases}

Besides the HCV-related conditions described above, other rheumatic diseases have been suggested to be associated with HCV infection; namely, osteosclerosis, myalgia, fibromyalgia, poly/dermatomyositis, polyarteritis nodosa, Beçhet's syndrome, systemic lupus erythematosus, and antiphospholipid syndrome $[1,8,9,29]$.

Osteosclerosis is a very uncommon condition described in adults infected with HCV and can be defined as an acquired, painful skeletal disorder characterized by a marked increase of bone mass [37-40]. Clinically, osteosclerosis is characterized by nonspecific, often diffuse bony pain and tenderness over involved bones due to periosteal stretching, in the absence of joint swelling or motion limitation. Radiographic examination shows bony sclerosis and thickening of the long-bone cortices, mainly diaphyseal cortical bone. Laboratory investigations frequently reveal abnormally increased markers of bone formation (alkaline phosphatase, bone-specific alkaline 


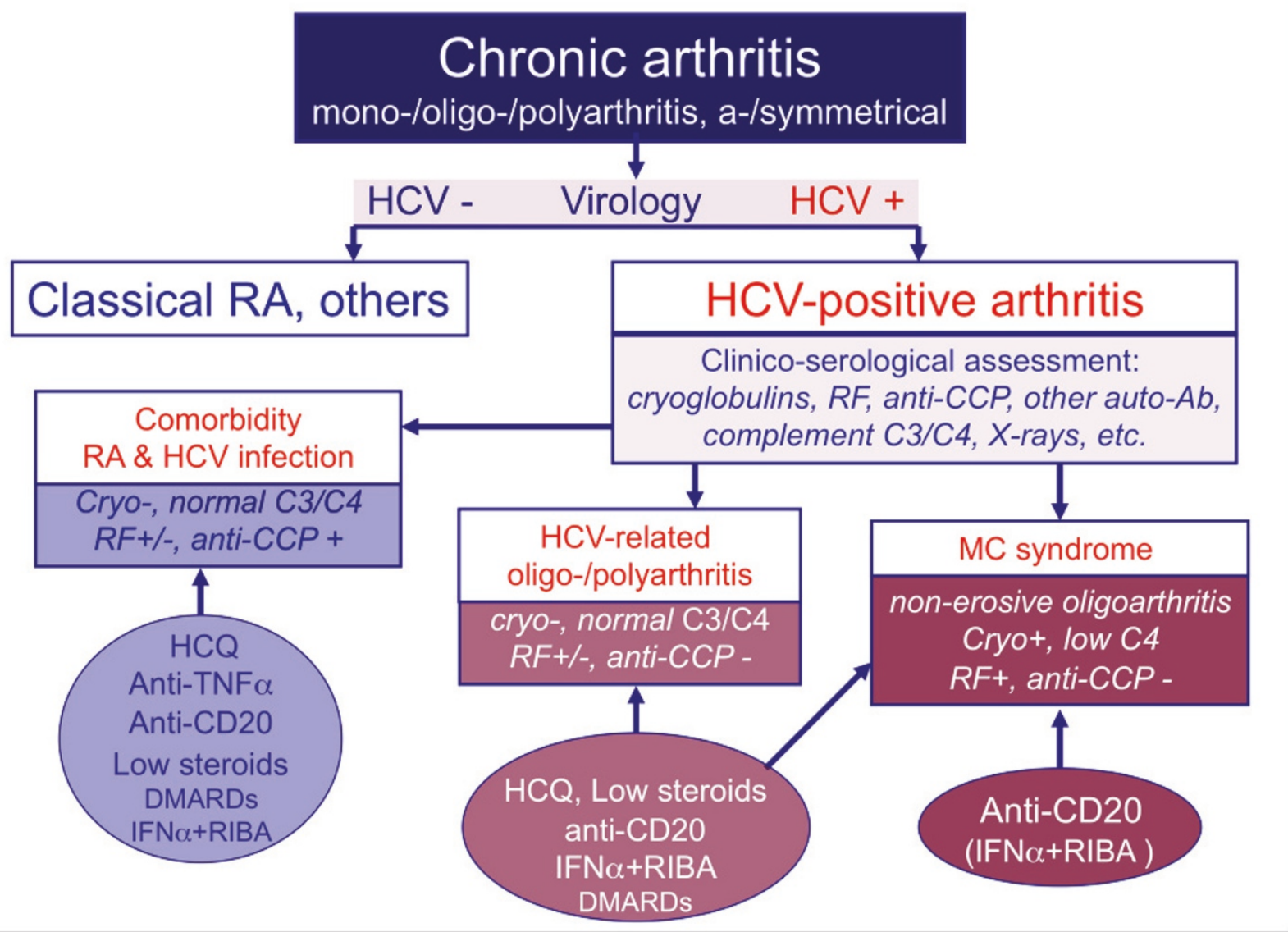

Figure 6. Differential diagnosis among patients with arthritis and concomitant hepatitis $\mathrm{C}$ virus infection, and therapeutic strategies. Clinico-serological and virological work-up is mandatory in patients presenting with chronic arthritis. Patients with polyarthritis and hepatitis $C$ virus (HCV) infection can be classified as either having simple comorbidity, that is, HCV infection and rheumatoid arthritis (RA) or other forms of chronic arthritis, or having HCV-associated arthritis. This latter may represent one extrahepatic manifestation of HCV infection or it can be a symptom of MCs. The comorbidity may be treated with the standard therapeutic strategies for RA, with some precautions because of concomitant viral infection, in particular for methotrexate and leflunomide. On the contrary, biologics (anti-TNFa and anti-CD20 rituximab) have been usefully employed without significant side effects in HCV-positive RA patients. The antiviral therapy of IFNa plus ribavirin (RIBA) can also be employed after careful hepatologic evaluation of patients. Interestingly, anti-TNFa, rituximab, and cyclosporine A seem to have a potential synergistic effect if associated with antiviral treatment (IFNa + RIBA). Usually, HCV-associated arthritis is poorly aggressive and may respond to low doses of steroids and hydroxychloroquine (HCQ). The use of other disease-modifying anti-rheumatic drugs (DMARDs) presents the above-mentioned limitations, while rituximab may be usefully employed, especially in patients with more aggressive arthritis. Finally, rituximab may represent the first-choice treatment in patients with arthritis in the setting of MCs. Ab, antibody; CCP, cyclic citrullinated peptide; RF, rheumatoid factor.

phosphatase, and osteocalcin); these alterations were mirrored by the marked increase of bone mass (bone mineral density) and enhanced radionuclide uptake at scintigraphy $\left({ }^{99 \mathrm{~m} T c-M D P}\right)$. Bone biopsy shows increased numbers and thickness of trabeculae with parallel reduction of bone marrow [37-40]. The pathogenesis of this rare syndrome is still unknown. It has been suggested that HCV alone or in combination with other unknown agent(s) may infect and alter bone cells or their precursors in predisposed subjects. These alterations might be mediated by the production of bone growth factors, such as insulin-like growth factors or osteoprotegerin. The pathogenetic role of this latter factor seems to be relevant as an imbalance in the osteoprotegerin/RANKL (receptor activator of nuclear factor kappa-B ligand) system leading to a predominance of osteoprotegerin has been documented [38]. With regards to therapeutic approaches to osteosclerosis, attempts to treat with antiresorptive agents in at least seven patients was ineffective, while symptomatic treatments may provide some benefit. In some cases a partial or complete spontaneous remission of symptoms and/or bone sclerosis was 
observed during follow-up [37-40]. Anecdotally, in a recently published case report the antiviral therapy was followed by a recovery of skeletal sclerosis [40].

Myalgia has been recorded in a significant number (15\%) of patients from a large series of HCV-infected individuals [29]. The pathogenesis of this symptom remains difficult to explain, although the detection of viral genomic sequences within muscle fibers suggested a direct involvement of $\mathrm{HCV}$ in the pathogenesis of diffuse muscle pain [41]. Fibromyalgia has also been reported by some studies in a significant percentage of patients with chronic HCV infection [42], but other studies in series of patients with typical fibromyalgia have not confirmed this association $[9,43]$. On the other hand, the differential diagnosis between fibromyalgia and muscle pain, frequently associated with weakness and arthralgias, may be very difficult in the setting of HCV-positive patients. With regard to sicca syndrome and pSS, some authors prefer to maintain $\mathrm{HCV}$-associated myalgia and classical fibromyalgia as distinct entities $[9,43]$.

Several case reports in the literature have documented an association between poly-dermatomyositis and $\mathrm{HCV}$ infection $[1,8,9,29,44]$. Generally, these disorders appear in patients with long-lasting viral infection or may complicate IFN $\alpha$ treatment [45]. Similarly, cases of vasculitis involving medium-sized arteries suggesting the diagnosis of polyarteritis nodosa have been associated with $\mathrm{HCV}$ infection $[29,46]$. In addition, HCV seropositivity has been reported in a significant percentage of patients with polyarteritis nodosa [46]. This possible association is not surprising considering the well-known relationship between polyarteritis nodosa and another hepatotropic virus, hepatitis B virus, which is responsible for a significant number of patients with this vasculitis [47]. Polyarteritis nodosa may share numerous clinical symptoms with MCs; thus, patients with suspected HCVassociated polyarteritis nodosa should be correctly classified by means of wide clinico-serological and pathological work-up.

With regard to other possible HCV-associated disorders, namely Beçhet's syndrome, systemic lupus erythematosus, and antiphospholipid syndrome, data reported in the literature are generally anecdotal $[8,9,29,48,49]$. Even if a possible causative role of $\mathrm{HCV}$ in these autoimmune diseases cannot be totally excluded, these patients might be better classified as having a simple comorbidity. However, they invariably represent a troublesome clinical condition, mainly with regards to therapeutic approach.

As for HCV-associated MCs, patients with concomitant autoimmune systemic disorders, such as poly/ dermatomyositis, polyarteritis nodosa, systemic lupus erythematosus, and HCV infection may be usefully treated with immunesuppressors (for example, cyclophosphamide and rituximab) with some important precautions and limitations due to viral infection. In all instances, a preliminary clinical evaluation of liver condition and viral replication is necessary before any therapeutic decisions are made. These latter may be based on standard immunosuppressive treatments, possibly integrated by sequential/combined antiviral treatment.

\section{Conclusion}

$\mathrm{HCV}$-associated disorders include a spectrum of different immunological and neoplastic manifestations, among which are some rheumatic diseases. On the basis of clinico-epidemiological, histopathological, and molecular biology studies, the strength of association between $\mathrm{HCV}$ and a given disease varies largely among different diseases and, more interestingly, for each disease among patient series from different countries.

Autoimmune systemic diseases often represent a clinical syndrome, which may include different clinicoserological subsets. These latter are the resulting phenotypes of multiple genetic, environmental, and infectious pathogenetic cofactors. MCs represents an important example of these multifactorial and clinically multifaceted disorders, potentially triggered by $\mathrm{HCV}$ infection in a variable percentage of cases. Considering the wide range of clinical phenotypes, some $\mathrm{HCV}$-associated diseases may present important classificatory/diagnostic difficulties, and may constitute a real therapeutic dilemma because of the coexistence of autoimmune manifestations and viral infection.

\section{Abbreviations \\ B-NHL, B-cell non-Hodgkin's lymphoma; DMARD, disease-modifying anti-rheumatic drug; $H C V$, hepatitis $C$ virus; IFN, interferon; MCs, mixed cryoglobulinemia syndrome; pSS, primary Sjögren's syndrome; RA, rheumatoid arthritis; TNF, tumor necrosis factor.}

\section{Competing interests}

The authors declare that they have no competing interests.

\section{Author details}

'Rheumatology Unit, University of Modena and Reggio Emilia School of Medicine, 41100 Modena, Italy. ${ }^{2}$ Department of Internal Medicine, Metabolism Unit, University of Pisa School of Medicine, Pisa, 56100, Italy.

Published: 25 June 2012

\section{References}

1. Ferri C: Mixed cryoglobulinemia. Orphanet J Rare Dis 2008, 3:25

2. Dammacco F, Sansonno D, Piccoli C, Racanelli V, D'Amore FP, Lauletta G: The lymphoid system in hepatitis $C$ virus infection: autoimmunity, mixed cryoglobulinemia, and overt B-cell malignancy. Semin Liver Dis 2000, 20:143-157.

3. Ferri C, Cacoub P, Mascia MT, Saadoun D: Cryoglobulinemia and systemic manifestations of hepatitis C virus. In EULAR Compendium on Rheumatic Diseases. London, BMJ Publishing Group Ltd; 2009:616-635.

4. Ferri C, Antonelli A, Mascia MT, Sebastiani M, Fallahi P, Ferrari D, Pileri SA, Zignego AL: HCV-related autoimmune and neoplastic disorders: the HCV syndrome. Dig Liver Dis 2007, 39 Suppl 1:S13-21.

5. Zignego AL, Macchia D, Monti M, Thiers V, Mazzetti M, Foschi M, Maggi E, Romagnani $S$, Gentilini $P$, Bréchot $C$ : Infection of peripheral mononuclear blood cells by hepatitis C virus. J Hepatol 1992, 15:382-386. 
6. Lunel F, Musset L, Cacoub P, Frangeul L, Cresta P, Perrin M, Grippon P, Hoang C, Valla D, Piette JC: Cryoglobulinemia in chronic liver diseases: role of hepatitis C virus and liver damage. Gastroenterology 1994, 106:1291-1300.

7. Zignego AL, Ferri C, Giannelli F, Giannini C, Caini P, Monti M, Marrocchi EM, Di Pietro E, La Villa G, Laffi G, Gentilini P: Prevalence of BCL-2 rearrangement in hepatitis $C$ virus-related mixed cryoglobulinemia with or without complicating B-cell lymphoma. Ann Intern Med 2002, 137:571-580.

8. Buskila D: Hepatitis C-associated rheumatic disorders. Rheum Dis Clin North Am 2009, 35:111-123.

9. Lormeau C, Falgarone G, Roulot D, Boissier MC: Rheumatologic manifestations of chronic hepatitis C infection. Joint Bone Spine 2006, 73:633-638.

10. De Vita S, Soldano F, Isola M, Monti G, Gabrielli A, Tzioufas A, Ferri C, Ferraccioli GF, Quartuccio L, Corazza L, De Marchi G, Casals MR, Voulgarelis M, Lenzi M, Saccardo F, Fraticelli P, Mascia MT, Sansonno D, Cacoub P, Tomsic M, Tavoni A, Pietrogrande M, Zignego AL, Scarpato S, Mazzaro C, Pioltelli P, Steinfeld S, Lamprecht P, Bombardieri S, Galli M: Preliminary classification criteria for the cryoglobulinaemic vasculitis. Ann Rheum Dis 2011, 70:1183-1190.

11. Monti G, Galli M, Invernizzi F, Pioltelli P, Saccardo F, Monteverde A, Pietrogrande M, Renoldi P, Bombardieri S, Bordin G, Candela M, Ferri C, Gabrielli A, Mazzaro C, Migliaresi S, Mussini C, Ossi E, Quintiliani L, Tirri G, Vacca A; GISC, Italian Group for the Study of Cryoglobulinaemias: Cryoglobulinaemias: a multi-centre study of the early clinical and laboratory manifestations of primary and secondary disease. QJM 1995, 88:115-126.

12. Zuckerman E, Keren D, Slobodin G, Rosner I, Rozenbaum M, Toubi E, Sabo E, Tsykounov I, Naschitz JE, Yeshurun D: Treatment of refractory, symptomatic, hepatitis $\mathrm{C}$ virus related mixed cryoglobulinemia with ribavirin and interferon-alpha. J Rheumatol 2000, 27:2172-2178.

13. Mazzaro C, Zora F, Caizzi M, Donada C, Di Gennaro G, Dal Maso K, Carniello G, Virgolini L, Tirelli U, Pozzato G: Treatment with peg interferon alfa-2b and ribavirin of hepatitis C virus-associated mixed cryoglobulinemia: a pilot study. J Hepatol 2005, 42:632-638.

14. Lidove O, Cacoub P, Hausfater P, Wechsler B, Frances C, Leger JM, Piette JC: Cryoglobulinemia and hepatitis $C$ : worsening of peripheral neuropathy after interferon alpha treatment. Gastroenterol Clin Biol 1999, 23:403-406.

15. Toussaint NC, Maman $Y$, Kohlbacher O, Louzoun $Y$ : Universal peptide vaccines - Optimal peptide vaccine design based on viral sequence conservation. Vaccine 2011, 29:8745-8753.

16. Galeazzi M, Bellisai F, Manganelli S, Morozzi G, Sebastiani GD: Cyclosporine A for the treatment of autoimmune disorders in HCV infected patients. Autoimmun Rev 2006, 5:493-498.

17. Zein NN, for the Etanercept Study Group: Etanercept as an adjuvant to interferon and ribavirin in treatment-naive patients with chronic hepatitis C virus infection: a phase 2 randomized, double-blind, placebo-controlled study. J Hepatol 2005, 42:315-322.

18. Ferri C, Cacoub P, Mazzaro C, Roccatello D, Scaini P, Sebastiani M, Tavoni A, Zignego AL, De Vita S: Treatment with rituximab in patients with mixed cryoglobulinemia syndrome: Results of multicenter cohort study and review of the literature. Autoimmun Rev 2011, 11:48-55

19. Petrarca A, Rigacci L, Caini P, Colagrande S, Romagnoli P, Vizzutti F, Arena U, Giannini C, Monti M, Montalto P, Matucci-Cerinic M, Bosi A, Laffi G, Zignego AL: Safety and efficacy of rituximab in patients with hepatitis $C$ virus related mixed cryoglobulinemia and severe liver disease. Blood 2010, 116:335-342.

20. De Vita S, Quartuccio L, Isola M, Mazzaro C, Scaini P, Lenzi M, Campanini M, Naclerio C, Tavoni A, Pietrogrande M, Ferri C, Mascia MT, Masolini P, Zabotti A, Maset M, Roccatello D, Zignego AL, Pioltelli P, Gabrielli A, Filippini D, Perrella O, Migliaresi S, Galli M, Bombardieri S, Monti G: A randomized controlled trial of rituximab for the treatment of severe cryoglobulinemic vasculitis. Arthritis Rheum 2012, 64:843-853.

21. Ferri C, Pietrogrande M, Cecchetti C, Tavoni A, Cefalo A, Buzzetti G, Vitali C, Bombardieri S: Low-antigen-content diet in the treatment of mixed cryoglobulinemia patients. Am J Med 1989, 87:519-524.

22. Stefanutti C, Di Giacomo S, Mareri M, De Lorenzo F, D'Alessandri G, Angelico F, Bucci A, Musca A, Mammarella A: Immunoadsorption apheresis (Selesorb) in the treatment of chronic hepatitis $C$ virus-related type 2 mixed cryoglobulinemia. Transfus Apher Sci 2003, 28:207-214.

23. Falanga V: Wound bed preparation: future approaches. Ostomy Wound Manage 2003, 49 Suppl 5:30-33.

24. Frykberg RG, Driver VR, Carman D, Lucero B, Borris-Hale C, Fylling CP, Rappl
LM, Clausen PA: Chronic wounds treated with a physiologically relevant concentration of platelet-rich plasma gel: a prospective case series. Ostomy Wound Manage 2010, 56:36-44.

25. Saadoun D, Resche Rigon M, Sene D, Terrier B, Karras A, Perard L, Schoindre Y, Coppéré B, Blanc F, Musset L, Piette JC, Rosenzwajg M, Cacoub P: Rituximab plus Peg-interferon-alpha/ribavirin compared with Peg-interferon-alpha/ ribavirin in hepatitis C-related mixed cryoglobulinemia. Blood 2010, 116:326-334.

26. Dammacco F, Tucci FA, Lauletta G, Gatti P, De Re V, Conteduca V, Sansonno S, Russi S, Mariggiò MA, Chironna M, Sansonno D: Pegylated interferon-alpha, ribavirin, and rituximab combined therapy of hepatitis $C$ virus-related mixed cryoglobulinemia: a long-term study. Blood 2010, 116:343-353.

27. Pietrogrande M, De Vita S, Zignego AL, Pioltelli P, Sansonno D, Sollima S, Atzeni F, Saccardo F, Quartuccio L, Bruno S, Bruno R, Campanini M, Candela M, Castelnovo L, Gabrielli A, Gaeta GB, Marson P, Mascia MT, Mazzaro C, Mazzotta F, Meroni P, Montecucco C, Ossi E, Piccinino F, Prati D, Puoti M, Riboldi P, Riva A, Roccatello D, Sagnelli E, et al.: Recommendations for the management of mixed cryoglobulinemia syndrome in hepatitis $C$ virusinfected patients. Autoimmun Rev 2011, 10:444-454

28. Vitali C: Immunopathologic differences of Sjögren's syndrome versus sicca syndrome in HCV and HIV infection. Arthritis Res Ther 2011, 13:233.

29. Cacoub P, Poynard T, Ghillani P, Charlotte F, Olivi M, Piette JC, Opolon P. Extrahepatic manifestations of chronic hepatitis C. MULTIVIRC Group. Arthritis Rheum 1999, 42:2204-2212.

30. Toussirot E, Le Huede G, Mougin C, Balblanc JC, Bettinger D, Wendling D: Presence of hepatitis $C$ virus RNA in the salivary glands of patients with Sjogren's syndrome and hepatitis C virus infection. J Rheumatol 2002, 29:2382-2385.

31. Ioannidis JPA, Vassiliou VA, Moutsopoulos HM: Long term risk of mortality and lymphoproliferative disease and predictive classification of primary Sjögren's syndrome. Arthritis Rheum 2002, 46:741-747.

32. Doffoël-Hantz V, Loustaud-Ratti V, Ramos-Casals M, Alain S, Bezanahary H, Liozon E, Fauchais AL, Vidal E: Evolution of Sjögren syndrome associated with hepatitis $C$ virus when chronic hepatitis $C$ is treated by interferon or the association of interferon and ribavirin. Rev Med Interne 2005, 26:88-94.

33. Bombardieri M, Alessandri C, Labbadia G, lannuccelli C, Carlucci F, Riccieri V, Paoletti V, Valesini G: Role of anti-cyclic citrullinated peptide antibodies in discriminating patients with rheumatoid arthritis from patients with chronic hepatitis $C$ infection-associated polyarticular involvement. Arthritis Res Ther 2004, 6:137-141.

34. Palazzi C, Olivieri I, Cacciatore P, Pennese E, D'Amico E: Difficulties in the differential diagnosis between primitive rheumatic diseases and hepatitis C virus-related disorders. Clin Exp Rheumatol 2005, 23:2-6.

35. Ferri C, Govoni M, Calabrese L: The A, B, Cs of viral hepatitis in the biologic era. Curr Opin Rheumatol 2010, 22:443-450.

36. Ferri C, Ferraccioli G, Ferrari D, Galeazzi M, Lapadula G, Montecucco C, Triolo G, Valentini G, Valesini G; GISEA Group: Safety of anti-tumor necrosis factoralfa therapy in patients with rheumatoid arthritis and chronic hepatitis C virus infection. J Rheumatol 2008, 35:1944-1949.

37. Villareal DT, Murphy WA, Teitelbaum SL, Arens MQ, Whyte MP: Painful diffuse osteosclerosis after intravenous drug abuse. Am J Med 1992, 93:371-381.

38. Manganelli P, Giuliani N, Fietta P, Mancini C, Lazzaretti M, Pollini A, Quaini F, Pedrazzoni M: OPG/RANKL system imbalance in a case of hepatitis Cassociated osteosclerosis: the pathogenic key? Clinical Rheum 2005, 24:296-300.

39. Tanaka T, Oki S, Muro S, Tanaka K, Hashimoto J: A case of hepatitis Cassociated osteosclerosis in an elderly Japanese man. Endocrine J 2006, 53:393-399.

40. Javier RM, de Vernejoul MC, Afif N, Kuntz UL, Sibilia J: Skeletal recovery from hepatitis $\mathrm{C}$-associated osteosclerosis (HCAO) following antiviral treatment. Joint Bone Spine 2011, 78:409-411.

41. Ito H, Ito H, Nagano M, Nakano S, Shigeyoshi Y, Kusaka H: In situ identification of hepatitis C virus RNA in muscle. Neurology 2005, 64:1073-1075.

42. Kozanoglu E, Canataroglu A, Abayli B, Colakoglu S, Goncu K: Fibromyalgia syndrome in patients with hepatitis C infection. Rheumatol Int 2003, 23:248-251.

43. Narváez J, Nolla JM, Valverde-García J: Lack of association of fibromyalgia with hepatitis C virus infection. J Rheumatol 2005, 32:1118-1121.

44. Fiore G, Giacovazzo F, Giacovazzo M: HCV and dermatomyositis: report of 5 cases of dermatomyositis in patients with HCV infection. Riv Eur Sci Med 
Farmacol 1996, 18:197-201.

45. Aouba A, Georgin-Lavialle S, Terrier B, Guillevin L, Authier FJ: Anti-PL7 antisynthetase syndrome under interferon therapy. Joint Bone Spine 2011, 78:94-97.

46. Saadoun D, Terrier B, Semoun O, Sene D, Maisonobe T, Musset L, Amoura Z, Rigon MR, Cacoub P: Hepatitis C virus-associated polyarteritis nodosa. Arthritis Care Res 2011, 63:427-435.

47. Terrier B, Cacoub P: Hepatitis B virus, extrahepatic immunologic manifestations and risk of viral reactivation. Rev Med Interne 2011, 32:622-627.

48. Erkek E, Ayaslioglu E: Hepatitis C virus and Behcet's disease. J Gastroenterol Hepatol 2005, 20:1309.
49. Ramos-Casals M, Muñoz S, Medina F, Jara LJ, Rosas J, Calvo-Alen J, Brito-Zerón P, Forns X, Sánchez-Tapias JM; HISPAMEC Study Group: Systemic autoimmune diseases in patients with hepatitis $C$ virus infection: characterization of 1020 cases (The HISPAMEC Registry). J Rheumatol 2009, 36:1442-1448

doi:10.1186/ar3865

Cite this article as: Ferri C, et al.: Current treatment of hepatitis C-associated rheumatic diseases. Arthritis Research \& Therapy 2012, 14:215. 